\title{
Identificação dos principais smart cities suppliers, suas respectivas estratégias e nichos de mercado .
}

\section{Arthur Rodrigues Galli, leda Kanashiro Makiya}

\section{Resumo}

O presente projeto teve como objetivo, no primeiro momento, identificar quais eram as empresas que líderes na criação e distribuição de serviços e tecnologias para o segmento de cidades inteligentes. Além disso, em um segundo momento, buscou-se entender as estratégias de nicho de mercado. Por fim, com base no entendimento de quem são as principais smart cities suppliers, entendeu-se em quais segmentos atuavam.

\section{Palavras-chave:}

Cidades inteligentes, inovação, administração de empresas.

\section{Introdução}

O conceito de Smart Cities passou a ser conceituado acentuadamente recentemente dentro do meio acadêmico, em 2010, apesar da existência do termo já existir desde 1994. Tal fato acontece após o incentivo da União Europeia as cidades inteligentes, com o programa Horizon(1)

Com isso, juntamente ao surgimento do Big Data e a Inthernet of Things (IoT) as cidades inteligentes passaram a ser pautas dentro das grandes empresas de tecnologias bem como dos administradores das cidades pelo mundo.

Através disso, algumas corporações passaram a se destacar com o fornecimento de tecnologias para esse nicho, segundo a Navigant Research, 2017(2), essas empresas seriam a Cisco e Siemens, respectivamente.

\section{Resultados e Discussão}

No início da pesquisa sentiu-se a necessidade de entender o conceito de uma cidade inteligente, pois dessa forma seria possível entender se as smart cities supplier estariam alinhadas com elas. Então, com base na literatura já disponível encontrou quais eram os conceitos mais citados sobre o termo. Dentro dessa base, destaca-se aqui a seguinte:

"É a implementação e implantação de infraestruturas de tecnologia da informação e comunicação para apoiar o crescimento social e urbano através da melhoria da economia, do envolvimento dos cidadãos e da eficiência governamental."(3) Após o entendimento das cidades inteligentes, passou-se a buscar o que as empresas líderes (Woods \& Goldstein, 2017) estavam desenvolvendo, seus nichos e as suas estratégias.

Referindo-se, em primeiro lugar, as estratégias empregadas pelas smart cities supplier, pode-se destacar a existência de uma variedade expressiva de estratégias para a inovação tecnológicas, porém dentre elas as do tipo comportamental devem ser notadas neste momento (4).

Tabela 1. Estratégias de inovação tecnológicas, adaptado (5).

\begin{tabular}{|l|l|}
\hline Estratégia & Descrição \\
\hline Ofensiva & $\begin{array}{l}\text { Busca o aumento de } \\
\text { oportunidades de mercado, } \\
\text { explorando novas tecnologias e } \\
\text { licenças, com o investimento } \\
\text { pesado em ciência e tecnologia. }\end{array}$ \\
\hline
\end{tabular}

Além disso, foi mapeado quais tecnologias estavam sendo fornecidas por Cisco e Siemens, enquanto as líderes de merca, nos seguintes setores:

- Cisco:

lluminação, estacionamento, mobilidade urbana, segurança, centro de operações e resíduos sólidos, além dos programas de incentivos financeiros para adesão.

iemens:

mobilidade urbana, energético, desenvolvimento social, data analytics, segurança digital.

\section{Conclusões}

Através das revisão bibliográfica feita para entender o que é uma cidade inteligente, após o entendimento das estratégias de inovação, e dos nichos atuantes, concluiuse que as empresas líderes utilizam de um estratégia ofensiva conjuntamente com uma technology push, fazendo com que suas criações de tecnológicas sejam empurradas para o mercado e criando demanda para eles. Além disso, as empresas líderes pautam-se que uma cidade inteligente é baseada no uso de TIC's para seu desenvolvimento.

\section{Agradecimentos}

Agradeço a minha orientadora, leda Makya bem como toda a equipe do Sb-Lab da FCA - Unicamp pela ajuda ao decorrer do projeto.

Além de agradecer ao SAE e CNPQ pelo financiamento da iniciação científica.

\footnotetext{
Juceviius R, Patašien I, Patašius M. 146-150 ScienceDirect 19th International Scientific Conference; Economics and Management. Procedia - Soc Behav Sci [Internet]. 2014 [cited 2019 Jun 16];156:146-50. Available from: www.sciencedirect.com

Woods E, Goldstein N. Navigant Research Leaderboard Report: Smart City Suppliers. Assessment of Strategy and Execution for 15 Smart City Suppliers. 2017;53. Available from: http://www.ibm.com/smarterplanet/global/files/us_en_us_smarter_cities_navigant_research_ report.pdf

Hollands RG. Will the real smart city please stand up? Online) J homepage [Internet]. 2008 [cited 2019 Jun 16];1470-3629. Available from: http://www.tandfonline.com/action/journalInformation?journalCode=ccit20:http://www.tandfon ine.com/loi/ccit20 